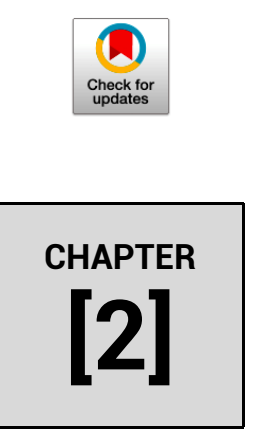

In: Environmental Degradation: Causes and Remediation Strategies

DOI: 10.26832/aesa-2020-edcrs-02

\title{
Role of natural disasters in environmental degradation: An overview
}

\begin{abstract}
Nitin Kamboj ${ }^{1}$, Aditi Bisht ${ }^{1, *}$, Vishal Kamboj ${ }^{1}$, Neeraj Pandey ${ }^{1}$ and Akanksha Bisht ${ }^{2}$

'Department of Zoology and Environmental Science, Gurukula Kangri Vishwavidyalaya, Haridwar-249404 (Uttarakhand), India

${ }^{2}$ Department of Medicinal and Aromatic Plants, Uttarakhand Altitude Plant Physiology Research Centre, Hemvati Nandan Bahuguna Garhwal University, Birla Campus, Srinagar-249161 (Uttarakhand), India
\end{abstract}

ABSTRACT

This chapter investigates the role of natural disasters in the degradation of the environment. In recent times, environmental degradation has become a matter of public concern. We studied the natural disasters occurring in the earth on the three types i.e. land, air and water. Globally, it is estimated that more than 100 types of disasters affect living beings and their environment. Therefore, this chapter, we have discussed the natural disasters, their causative phenomenon, types, causes and impacts on living beings including the form of deaths occurred worldwide. The sternness of a disaster is measured in lives lost, economic loss, and the skill of the inhabitants to rebuild. The life-threatening potential of any natural threat is assessed basically by its spatial degree and sternness. It has resulted in the degradation of the environment at an alarming rate. Mitigation plans are generally followed to protect the environment and reduce the adverse effect of disaster. Besides this, we also discussed the precaution, mitigation measures with do's and don'ts when natural disasters have happened.

KEYWORDS

Environmental degradation, Natural disasters, Precaution and mitigation

Aditi Bisht, Email: minnib18@gmail.com

(C) 2020 | Agro Environ Media | Agriculture and Environmental Science Academy, Haridwar, India 


\section{Introduction}

Nature is the physical and material world, including plants, animals, the landscape and other features and products of the Earth. In other words, it can be defined as the combination of flora and fauna including climatic conditions, geological and physical processes (Harper, 2006). Nature provides the raw materials such as forests, water, air, food, etc. for the survival of living beings. It maintains the environment through a cyclic process including hydrological cycle (maintain water) and geochemical cycles (NPK). There are numerous reasons for natural degradation, nearly all of them instilled in human technology. While some are the result of the unintentional consequences of technological advancement, others are examples of humans becoming too successful and efficient at resource abstraction. By minimalizing our involvement with problematic activities and supporting sustainable ones whenever possible, we can do our part to conserve the environment for upcoming generations. Natural disasters are any calamitous event that is caused by nature or the natural processes of the earth. The sternness of a disaster is measured in lives lost, economic loss, and the skill of the inhabitants to rebuild. The life-threatening potential of any natural threat is assessed basically by its spatial degree and sternness. Rising industrialization and unfair manipulation of natural resources have brought our ecosystem to a limit of non-reversibility and disproportion. This has directed to danger from a set of natural threats like contamination, global warming and ozone depletion on a big or global scale.

\section{Types of natural disasters}

In this chapter, we categorized natural disasters in three types on the basis of their occurrence, i.e. land-based, air-based, and water-based disasters (Figure 1).

\section{Land based disaster}

The land-based disasters are those which cause disturbances on the earth's surface. Some of them are earthquakes, landslides, volcanic eruption and avalanches.

Earthquakes: Earthquake is a phenomenon that occurs when the two tectonic plates of earth slide on one another (Ohnaka, 2013). The point from where earthquake start is the focus and the point directly above the focus on ground is epicenter seen in Figure 2. Earthquake is common of four types i.e. tectonic earthquake caused by tectonic plates; the induced earthquake caused by anthropogenic activities; the volcanic earthquake caused due to an active volcano and collapse earthquake caused due to cave-ins. An earthquake occurs every other day but the magnitude is so low that it is not experienced on the surface (Sibson, 1982; Vassiliou and Hiroo, 1982; Ohnaka, 


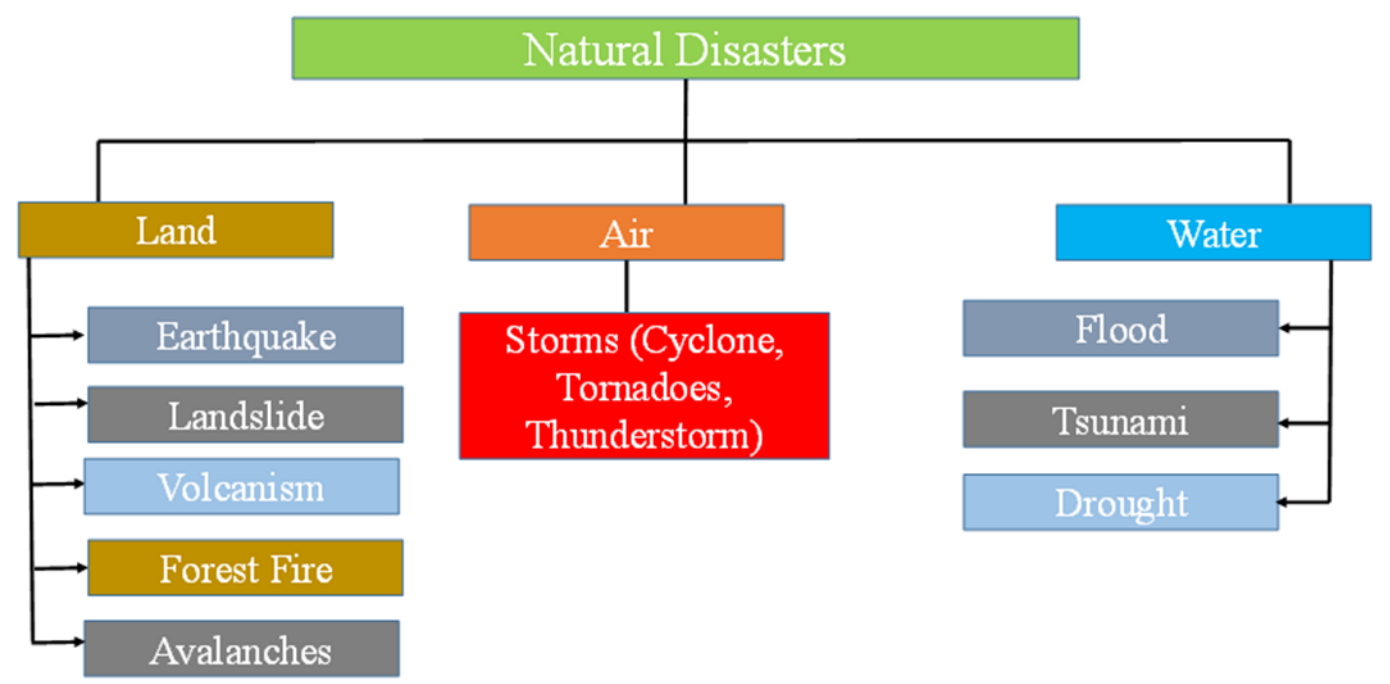

Figure 1. Types of natural disasters.

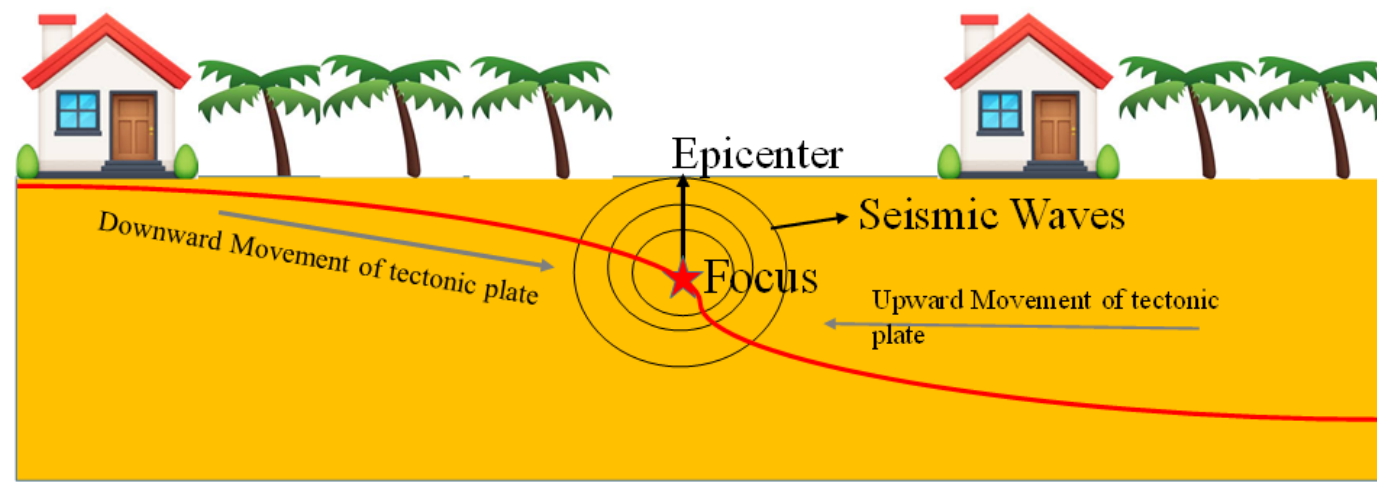

Figure 2. Pictorial diagram of earthquake. 
2013). According to Alden (2019), the major earthquake zones in the world are 20 (Table 1). The scientist divided these regions on the basis of their previous research, seismic activities and past earthquake records. Earthquake of magnitude 6.3 hit North India in September 2019 whose epicenter was said to be in Pakistan causing no loss of life in India but 50 people were injured and 1 was killed there (Times of India, 2019). Recently, the earthquake has been reported in the south Philippines of 6.9 magnitudes causing the death of 15 people. The epicenter of the earthquake was in Magsaysay town. The movement of tectonic plates on the Pacific Ring of Fire makes the Philippines is more prone to earthquakes.

Landslide: It is the sliding or flowing of the earth material formed of rock soils and earth fills. Landslide is a downward movement of soil or rock downhill (Hu et al., 2018). It occurs due to two reasons i.e. increase in shear tension and decrease in particle bond. The cause of landslides can be geographical, physical, morphological or human causes such as increasing population, deforestation, and change in the climate. In a hilly region, landslides are generally triggered by excessive rain, earthquakes and anthropogenic activities such as bomb blasting for construction of roads and for mining. There are three types of landslides that are divided into three principal groups i.e. slide, fall and topple. The slide-type landslide can be rotational or translational. In a rotational landslide, the movement of soil is in a rotational manner whereas in translational landslide the soil gets displaced downhill to the plane surface. Fall type landslide occurs because of the gravitational force (Mineral Resource Department, Fiji). The strong force leads to separation of huge rocks from parent rock and topple includes the frontward rotation and motion of rock, or regolith, of a slope at an axis lower than the center of gravity. Such a phenomenon occurs in steep cliffs only after large displacement of rock occur (USGS, 2004).

Table 1: Major Earthquakes zones around world.

\begin{tabular}{|c|c|}
\hline Continent & Area/country \\
\hline North America & $\begin{array}{l}\text { Alaska central coast to Anchorage and Fairbanks; British Columbia to Baja } \\
\text { California Peninsula; California's Central Valley and Southern California, } \\
\text { San Francisco Bay Area; Mexico; Western coast of Central America }\end{array}$ \\
\hline South America & $\begin{array}{l}\text { Caribbean coast of Colombia and Venezuela; Central Chile; Chilean capital } \\
\text { of Santiago; Peru }\end{array}$ \\
\hline Asia & $\begin{array}{l}\text { Japan; Indonesia; Fiji; Tonga; Sumatra; Russia; Norway; Central Asia; Black } \\
\text { sea; Iran; Caspian sea southern shores }\end{array}$ \\
\hline Europe & Iceland; Turkey; Mediterranean coast; Lisbon (Portuguese); Central Italy \\
\hline Africa & Lebanon, Western Tanzania \\
\hline $\begin{array}{l}\text { Australia and } \\
\text { New Zealand }\end{array}$ & Smaller neighbouring islands \\
\hline
\end{tabular}


In China, a landslide hit in the village of Xinmono and submerged 64 houses under the soil and killed about 10 people (Fan et al., 2017). In August 2019 landslide occurred in Wayanad, in the Western Ghats in which more than 50 people were killed (The Hindu, 2019).

Volcanism: When the lava, ashes, and gases come out of the opening, cracks or weak spots known as a vent from earth it is called volcanic eruptions. The movement of tectonic plates causes the eruption. The movement of plates creates pressure and forces molten rocks from the earth to explode in the air causing the outbreak. The molten lava when cools when forming a new earth crust. Some researcher also says that volcanic eruption may influence climate and is one of the climate changes (Forsyth, 1988; Foulger, 2010; Young, 2016). The volcano is categorized on the basis of explosiveness it is called Volcano Explosivity Index as given in Table 2 (Newhall and Self, 1982). The categories of VEI are as follows:

- Hawaiian type: In this type of volcano the lava is in a molten form that flows from the peak and cracks on the slopes. It has ejection volume $<104 \mathrm{~m}^{3}$ and Plume is $<100 \mathrm{~m}$.

- Strombolian type: Here the gases burst out with clots of molten lava with unceasing or cyclic eruptions. It has ejection volume $<104 \mathrm{~m}^{3}$ and the Plume is $100 \mathrm{~m}-1 \mathrm{~km}$. The Stromboli volcano is called the "lighthouse of the Mediterranean" because of its small and recurrent outbursts.

- Vulcanian type: The eruption forms dark-colored clouds It involves judicious bursts of gas and ashes. This mixture forms dark, turbulent clouds that rise and increase in different shapes.

- Pelean type: This type of eruption is explosive eruptions that produce a destructive mass of very hot and dense mixtures and gas. The ejection volume $>107 \mathrm{~m}^{3}$ and Plume is $3-5 \mathrm{~km}$.

- Plinian type: This is a violent volcanic eruption demonstrated by the eruption of Mount Vesuvius in Italy in AD 79. In this type of eruption, gases, hot magma generate nonstop blasts. The clouds formed by the ashes cause lightning strikes which pose one more fear to the outburst.

Forest Fire: A forest fire or wildfire is any uncontrolled fire generally in forest areas. The fire naturally occurs due to lightening through rain extinguishes such fires with no damage (Bruce and Kelli, 2009). High atmospheric temperatures and dry conditions make the perfect condition for a fire (Bowman et al., 2009). The fire may burn for days to weeks. It can burn the entire forest and even destroy organic matter. They are also known as grass fires, peat fires, forest fire and bush fires depending on undergrowth which are being burnt. Fire is generally experienced in summer when there is no rain for months and there is a lot of fuel in the form of leaves and twigs on the floor. There are generally 2 types of fire i.e. surface fire and crown fire. Surface fire is one 


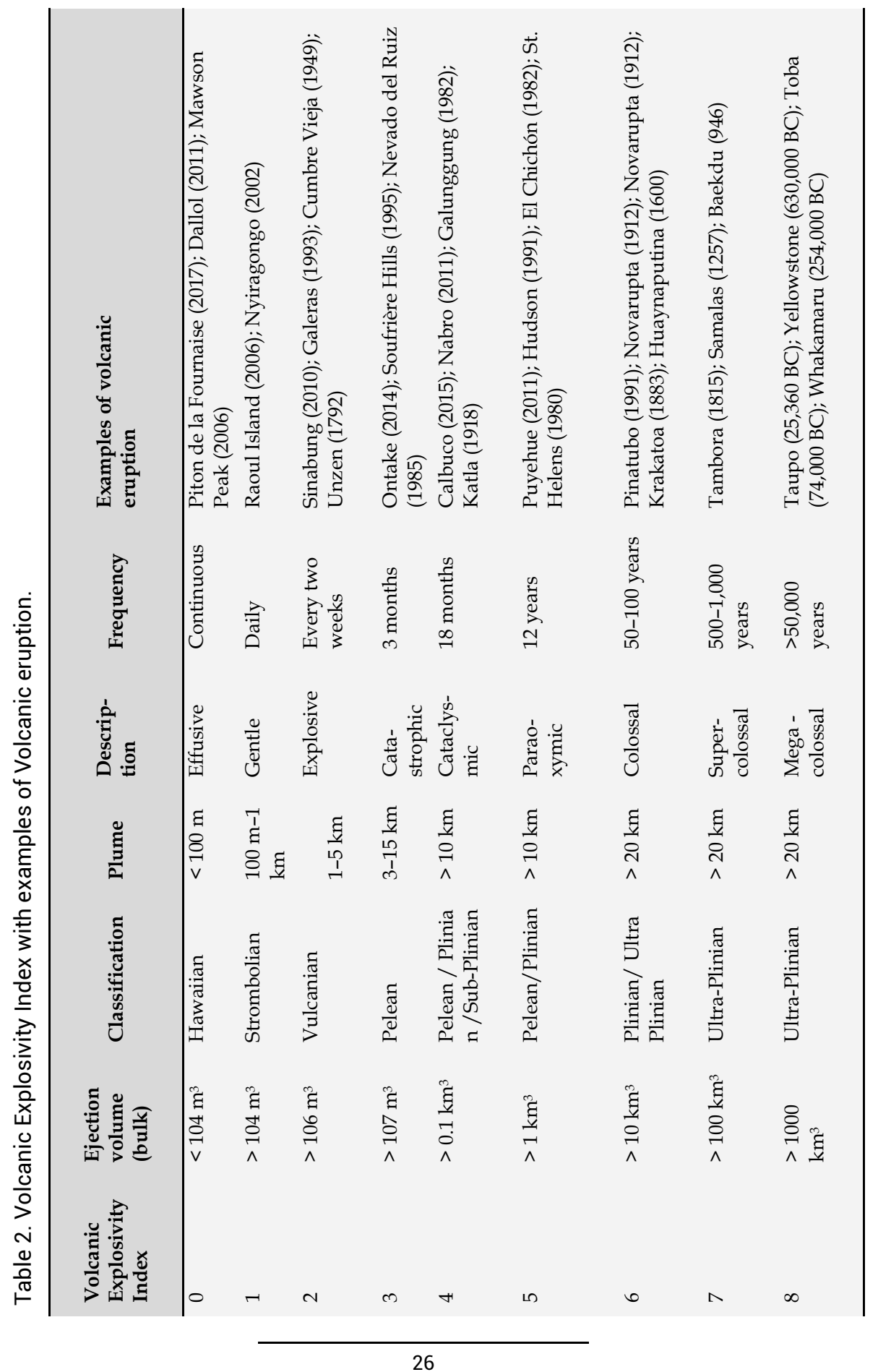


which is observed in the lower surface, it may be caused by leaf litter on the floor of the forest. The intensity of this type of fire is low to high. It affect the lower portion of the tree. The crown fire burns the crown of the tree. It may burn the tree and ultimately damaging forest canopy. The Garhwal and Kumaun Himalaya face the problem of forest fire regularly from the last few summers causing huge loss of biodiversity in 2016. Bargali et al. (2017) studied the fire frequency in Nainital, Uttarakhand. The area of Nainital district consisting of 55\% of no fire areas, $25 \%$ of Low fire zone, $18 \%$ of the medium fire area and $2 \%$ of high fire area out of the total geographical area.

Avalanche: Avalanche is the movement of snow due to the steep slope. It is generally spontaneous, and sometimes it is caused by an external agency (e.g. by humans or animals). It is controlled by the variability of snow, weather conditions and their interactions with topography (Schweizer et al., 2003). They cause serious danger to the people living in the Alpine areas. This phenomenon occurs throughout the year but is prominent in the winter months i.e. December to April especially in Northern Hemisphere. Avalanches are generally resulting from superimposing snow block and a weak base of the snow surface. They are generally of two types of release of avalanche i.e. loose and slab avalanche (Jamieson and Stethem, 2002; Schweizer et al., 2003). The snowstorm generates the highest risk of avalanches and it can be triggered by earthquakes and human activities. An avalanche in February 2019 in Italy killed 8 people including British and French skiers. Also, a recent avalanche collided at Siachen glacier at an altitude of $19,000 \mathrm{ft}$. at $3 \mathrm{pm}$ in the month of November. This killed 4 army men and 2 civilians.

\section{Air based disasters}

Air is a mixture of gases and dust particles. It is the surrounding earth's atmosphere. The disasters which are due to the air or wind are an air-based disaster. The air-based disaster is generally in the form of storms.

Storms: Storms are the heavy winds with damaging effects. These winds are due to irregular heating of the Earth. The winds are important for maintaining the water cycle. In Monsoon seasons, wind holds moisture which causes rain. Rains are very important for groundwater recharge, drinking purposes, and agriculture. But strong winds have a negative impact also, thunderstorms and cyclones cause devastation of property and life.

Thunderstorm: A combination of light and thunder forms a thunderstorm. It generally needs moisture to form clouds and ultimately rain, front like sea breeze or mountains which aids in lifting the warm air upwards and when the temperature rises it warms up the air. The warm air rises up and creates strong wind (Money, 2007). Thunderstorms are a typical event in Alabama, 
Mississippi, and Florida at any time of day. There are around 2,000 thunderstorms in progress every day but only $1 \%$ is considered as severe. The severe storms are characterized as 1 inch or bigger hail accompanied by strong winds. In the starting of May 2019, northern part of India specially the U.P. was hit by thunderstorm taking 134 lives injuring over 400 people. In Agra U.P. most deaths were reported. Dust storms and thunderstorms caused chaos in four states i.e. Uttar Pradesh, West Bengal, Andhra Pradesh and Delhi. This event leads to many deaths and causing huge destruction (The Economic Times, 2018).

Cyclones: Cyclones are ferocious storms moving in the spiral and combined by strong breezes and devastating rains. It is formed when the strong wind blows around the central area having low atmospheric pressure. As the water vaporizes, it consumes heat from the environment and later cools down. Cooled water changes into liquid and releases heat. This heat warms the air around it. The air then moves from high pressure to low pressure. This cycle goes on and forms a cyclone with low pressure in the center and high pressure around. The recent cyclone hit India in 2018, North Indian Ocean cyclone which was most active after 1992.

Tornadoes: Tornado is formed after thunderstorms which reach the ground as funnel-shaped cloud. It may have speed more than $400 \mathrm{~km}$ per hour. A tornado is very damaging to property. Tornadoes generally convert from one type to another. The types of tornadoes are rope tornadoes, cone tornadoes, wedge tornadoes, multi-vortex and satellite tornadoes, water and land spouts. The United States is more susceptible to the tornado. Damaging thunderstorms generally occur in South Dakota, Nebraska, Kansas, Oklahoma, northern Texas, and eastern Colorado. About 2000 people die every year due to tornadoes in the United States (Edward et al., 2013).

\section{Water based disasters}

Water is the main constituent of the earth's surface and is important for all living beings. The disaster which occurs due to water is termed as water-based disasters. The types of water-based disasters depend on the flow of water and the level of availability. The major types are as follows:

Floods: Flood is the overflowing of water over dry land areas. This is a common phenomenon occurring in India and most damage due to flood is seen in Asian countries. It generally occurs due to the overflowing river breaking of the dam, excessive rainfall, storm melting of snow or ice (Tingsanchali, 2012). Floods are generally of three types i.e. Fluvial, Pluvial and Coastal flood. The fluvial flood is when water overflows from a water body and reaches the nearby area. It is also known as the river flood. Pluvial floods are when heavy rain occurs and excess water is not absorbed by the earth. It can be in the form of flash flood and surface flood. Coastal flood is the submerging of coastal area in water. Storm surge is the type of coastal flood in which heavy 
winds force water on the shore. Flood is generally caused by a combination of heavy rainfall causing water body to overflow. Constructions of dams, roads and bridges, irrigation channels, houses, factories, manufacturing plants, bridges and culverts, farmlands and other activities of man have paved the way for free-flowing water into water bodies which leads to flood during heavy rain (Nwigwe and Emberga, 2014). The recent event of floods occurred in many parts of the world in 2019 example Iran, U.S., Houston, Midwestern U.S. flood and many more. In 2019 India encountered a sequence of floods that affected over thirteen states in the second half of the year 2019, because of continuous heavy rains. In this flood, more than 1500 people were reported dead between the month of June and October 2019 and many were evacuated. The two most affected states were Karnataka and Maharashtra (India Today, 2019).

Tsunami: Earthquake tremors or volcanic eruptions under the ocean form the giant waves which is known as Tsunami. The earthquake up thrusts the upliftment of seafloor and causes displacement of tonnes of water to set up the tsunami waves (Fradin and Brindell, 2008). The changes in the speed of a wave depend on the varying depth of the ocean. The speed of waves in tsunami reply on the depth of the ocean instead of the distance from the foundation of the wave. The speed of tsunami waves is relatively similar to the speed of jet plane. The wave speed slows down as soon as it reaches shallow waters. The tsunami waves are believed to travel at a speed of 500 miles an hour in the open ocean and attains a great height before it hits the shore. They can cause widespread devastation in coastal areas especially after the earthquake. The Tsunami of 2011 in Japan was caused by the undersea earthquake on the Eastern coast. Japan tsunami has killed over 15000 citizens and the waves hit the Fukushima nuclear plant (Fukada, 2011). In March 1964, an earthquake of 9.2 magnitudes occurred in Prince William region of Alaska. This earthquake created a horizontal displacement on the South coast of Alaska the coastal areas were raised by thirty feet. The land area of about 130,000 square kilometers was damaged in the earthquake. The Alaska earthquake, precursor activities, impacts on local communities, and what can do to prepare the earthquake in the future.

Drought: Drought is natural hazards which consist of a dry period without rain for a longer period of time (Bradford, 2000). This may cause scarcity of drinking water, destruction of agriculture crops, etc. which may lead to social and economic damage to the society. This occurs when the weather is interrupted, causing a problem to the water cycle (Mishra and Singh, 2010). Drought has been classified in two ways such as water cycle-based and level of severity (Figure 3). There are generally of 4 types of droughts (NOAA, 2006; Wang et al., 2015; Swain et al., 2019).

- Meteorological drought: It depends upon the precipitation and is area-specific For example, the southwest of the United States receive an average less than 3 inches (7.6 centimeters) 
precipitation per year, while the Northwest receives more than 150 inches $(381 \mathrm{~cm})$ per year, according to the U.S. Department of Interior.

- Agricultural drought: It depends on the water available to crops during growth stages.

- Hydrological drought: It is occurring when the water available is in less volume in streams, rivers, and reservoirs. Hydrological drought is generally linked with meteorological droughts.

- Socioeconomic drought: It occurs when more water is needed than supplied (Tate and Gustard, 2017).

Levels of severity: The index of levels of severity was developed by Wayne Palmer which is called the palmer drought severity index. It is a demand and supply model developed for soil moisture (Palmer, 1965). Drought is categorized into five levels of severity i.e. abnormally dry, moderate drought, severe drought, extreme drought, and exceptional drought (Dai, 2004).

- Abnormally dry: It is denoted by D0. The value of PDSI is between -1.0 and 1.9.

- Moderate drought: It is denoted by D1. The value of PDSI is between -2.0 and -2.9.

- Severe drought: It is denoted by D2. The value of PDSI is between -3.0 and -3.9.

- Extreme drought: It is denoted by D3. the value of PDSI is between -4.0 and -4.9 .

- Exceptional drought: It is denoted by D4. the value of PDSI is between -5.0 and -5.9.

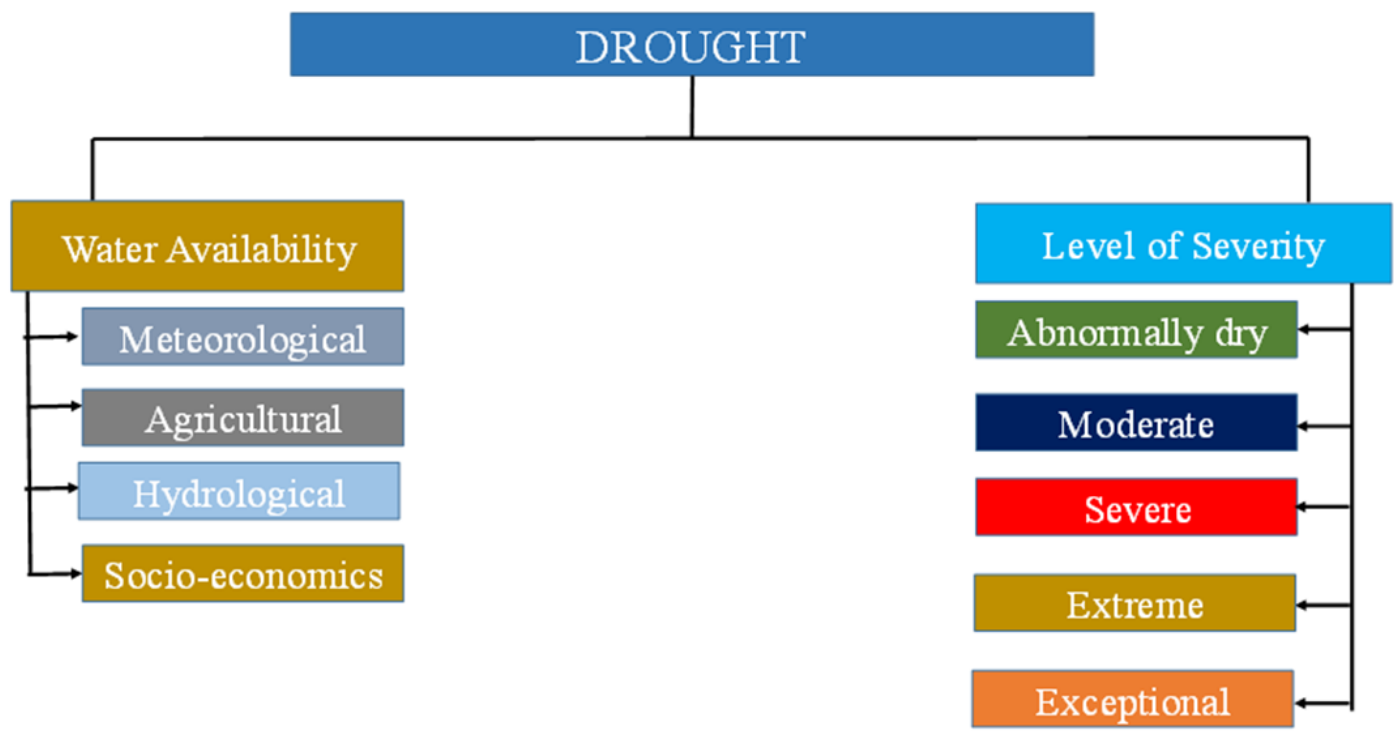

Figure 3. Types of drought. 


\section{Precautions, management, and mitigations}

Above we have discussed the disasters which occur due to natural agencies and their effect. Besides this, we should also know the precautions to deal with these disasters. The mitigation measures are divided into three phases i.e. before the disaster, during a disaster and after disaster described by the American Red Cross Society and National Institute of Disaster Management (NIDM).

Before disaster: There are common precautions to be kept in mind in hazard-prone areas as:

- $\quad$ First aid and fire extinguisher should be kept handy.

- Alert and early warning should be taken care of.

- Financial arrangements should be made.

- Keeping knowledge about the risk.

- A plan for evacuation should be prepared.

- Insurance of life, property and hazard type should be checked.

- Plan and conduct a mock drill with local people.

During disaster: There are many precautions to be taken during the disaster depending on the type and the intensity and level of severity of the disaster.

After disaster: Some disasters cause a lot of damage to life and property. After a disaster, check yourself for injuries and help people who require special assistance, listen to local people's radio and TV information regarding the update of the disaster.

Some specific measures to be taken during the particular natural disasters:

Earthquake: Earthquake causes huge damage to life and property. There are precautions that are taken to be safe during an earthquake. The area which is prone to earthquake should keep first aid and fire extinguisher handy. Heavy objects should not be kept on the shelves. When the earthquake hit the area people should not panic, should stay away from doors and windows and stay outdoor away from power lines. After the damage is done gas and electric lines should be checked and amended. First aid should be given to the needy.

Landslide: In a landslide, mitigation slopes are artificially made with the goal to reduce its effect (Cruden and Varnes, 1996). There are commonly three methods i.e. geometric methods, in which the geometry of hillside is altered; hydrogeological methods is when the water content is reduced and chemical and mechanical methods, where shear strength of unstable mass is increased.

Volcanism: Volcanism cannot be prevented but some steps can be taken before, during and after the volcano to reduce its impact. Before the volcanic eruption it is advised to be aware of the risk, 
make a plan for evacuation; during volcano safe place for shelter should be located and after volcanos, special care must be taken to protect yourself from the after-effects of volcanism like livestock should be kept indoor, full sleeves shirts and pants should be worn and special care should be taken to protect eyes.

Forest fire: The forest fire has become a menace for the forest biodiversity. We should take care of the fuel of fire like leaf litter and pine needles which helps the fire to ignite, campfire should not be left unattended, no matchstick and cigarettes should be left in the forest. During a fire, fire extinguishers should be called as soon as possible also the local people should come forward and help in extinguishing the fire (Bradstock et al., 2012).

Avalanche: There are generally two ways of mitigation in case of avalanche i.e. structural and non -structural. In non-structural we avoid the avalanche by evacuation and artificial triggering which help in the protection of valuable property. Afforestation is generally done for the protection and conservation of forests. Structural include building up dams and structures to avoid the heavy flow of snow (Ganju and Dimri, 2004; Eckert, 2008; Holub and Fuchs, 2008).

Storms: Storms are the heavy or circular wind that affects life and property. During the storm do not take shelter under the trees or under construction and damaged building. Move to the other side plant and stay away from flying object which may pose danger to you. If you are driving, do not out drive the wind it may be dangerous (Godschalk,1989; FEMA, 2011). Doppler radar, satellites, weather balloons, and computer helps in predicting tornadoes.

Flood: For the management of the flood, the overflow of water should be maintained. Watershed should be made, reservoir and small checks dams to reduce flow discharge are prepared. The river water should be distributed evenly in the neighboring, water channels should be prepared and flood embankment of the area should be done to avoid overflowing during heavy rain (Vogt and Somma, 2013).

Tsunami: The effect of a tsunami can only be reduced it cannot be prevented. During the tsunami, it is advised to evacuate to higher areas from the location and carry food, important documents, first aid with you. During the tsunami lay down powerlines, and buildings should be avoided and after return to your place only when declared safe from authorities (Harada and Imamura, 2005; Bernard, 2006).

Drought: Drought is caused due to scarcity of water. Before the disaster, it is advised not to wastewater, and use energy-efficient and water-efficient appliances and do rainwater harvesting. 


\section{Conclusion}

The present book chapter has focused on the natural disaster and its effect on the environment. The natural disaster in this paper is divided into three bases i.e. land, air, and water-based disasters. Due to the unsustainable use of natural resources the intensity of the natural disaster has increased. It has resulted in the degradation of the environment at an alarming rate. Mitigation plans are generally followed to protect the environment and reduce the adverse effect of disaster. They are divided into three phases that i.e. before, during and after a disaster. Some key mitigation measures such as keeping first aid handy, making evacuation plan and conducting mock drills. Also, public awareness through TV programs, radio and school education is the need of the hour.

\section{Conflict of Interest}

There is no conflict of interest.

\section{Acknowledgment}

The authors highly thank the Department of Zoology and Environmental Science, Gurukula Kangri Vishwavidyalaya for providing the facilities and also to my supervisor (Dr. Nitin Kamboj) for guiding me.

\section{References}

Alley, W. (1984). The Palmer Drought Severity Index: Limitations and Assumptions, Journal of Climate and Applied Meteorology, 23: 1100-1109.

Anonymous (2019). Four Army personnel, two porters killed in avalanche in Siachen glacier. The Economic Times. Retrieved from https:// economictimes.indiatimes.com/news.

Bargali, H., Gupta, S., Malik, D.S. and Gagan, M. (2017). Estimation of fire frequency in Nainital district of Uttarakhand state by using satellite images. Journal of Remote Sensing and GIS, 6: 214. doi: 10.4172/2469-4134.100021.

BBC News (2019). Italy avalanche kills British and French skiers, BBC News, https://www.bbc.com/news.

Bernard, E.N., Mofjeld, H.O., Titov, V., Synolakis, C.E. and González, F.I. (2006). Tsunami: scientific frontiers, mitigation, forecasting and policy implications. Philosophical Transactions of the Royal Society A: Mathematical, Physical and Engineering Sciences, 364(1845): 1989-2007.

Bowman, D.M.J.S., Balch, J.K., Artaxo, P., Bond, W.J., Carlson, J.M., Cochrane, M.A. (2009). Fire in the Earth system. Science, 324(5926): 481-484. doi:10.1126/science.1163886.

Bradford, R.B. (2000). Drought events in Europe. In drought and drought mitigation in Europe. Springer, Dordrecht. 7-20.

Bradstock, R.A., Cary, G.J., Davies, I., Lindenmayer, D.B., Price, O.F. and Williams, R.J. (2012). Wildfires, fuel treatment and risk mitigation in Australian eucalypt forests: insights from landscape-scale simulation. Journal of Environmental Manage- 
ment, 105: 66-75

Cruden D.M. and Varnes D.J. (1996). Landslide types and process. In "Landslides - Investigation and Mitigation", Transportation Research Board Special Report n. 247, National Academy Press, Washington DC, 36-75.

Dai, A., Trenberth, K.E. and Qian, T. (2004). A global dataset of Palmer Drought Severity Index for 1870-2002: Relationship with soil moisture and effects of surface warming. Journal of Hydrometeorology, 5(6): 1117-1130.

Dosseto, A. (2011). Global Volcanism Program - Hoodoo Mountain"(volcano.si.edu.), Turner, S. P.; Van-Orman, J. A. (eds.). Timescales of Magmatic Processes: From Core to Atmosphere. Wiley-Blackwell.

Eckert, N., Parent, E., Faug, T. and Naaim, M. (2008). Optimal design under uncertainty of a passive defense structure against snow avalanches: from a general Bayesian framework to a simple analytical model. Natural Hazards and Earth System Sciences, 8(5): 1067-1081.

Edwards, R., Ladue, J.G., Ferree, J.T., Scharfenberg, K., Maier, C., Coulbourne and William L. (2013). Tornado Intensity Estimation: Past, Present, and Future. Bulletin of the American Meteorological Society, 94(5): 641-653. doi:10.1175/BAMS-D-1100006.1.

El Haggar, S. (2010). Sustainable industrial design and waste management: cradle-to-cradle for sustainable development. Academic Press.

Fan, X., Xu, Q. and Scaringi, G. (2017). Failure mechanism and kinematics of the deadly June 24th 2017 Xinmo landslide, Maoxian, Sichuan, China. Landslides, 14(6): 2129-2146. doi:10.1007/s10346-017-0907-7.

Federal Emergency Management Agency (FEMA; 2011). Thunderstorm and Lightning Ready. US Department of Homeland Security. Archived from the original on 23 June 2011. Retrieved 24 August 2011.

Forsyth, P.Y. (1988). In the wake of Etna, 44 B.C. Classical Antiq., 7: 49-57.

Foulger, G.R. (2010). Plates vs. Plumes: A Geological Controversy. Wiley-Blackwell.

Fradin, J.B. and Brindell, D. (2008). Witness to Disaster: Tsunamis. Witness to Disaster. Washington, D.C.: National Geographic Society. pp. 42-43.

Fukada, T. (2011). Iwate fisheries continue struggle to recover. The Japan Times. p. 3. Retrieved 2016-09-18.

Ganju, A. and Dimri, A.P. (2004). Prevention and mitigation of avalanche disasters in western Himalayan region. Natural hazards, 31(2), 357-371.

Godschalk, D.R., Brower, D.J. and Beatley, T. (1989). Catastrophic coastal storms: Hazard mitigation and development management. Duke University Press.

Harada, K. and Imamura, F.U.M.I.H.I.K.O. (2005). Effects of coastal forest on tsunami hazard mitigation - a preliminary investigation. In Tsunamis (pp. 279-292). Springer, Dordrecht.

Harper, D. (2006). Nature. Online Etymology Dictionary. http://www.etymonline.com/index.php?term=nature.

Holub, M. and Fuchs, S. (2008). Benefits of local structural protection to mitigate torrent-related hazards. WIT Transactions on Information and Communication Technologies, 39: 401-411

Hu, W., Scaringi, G., Xu, Q., Van, A. and Theo, W.J. (2018). Suction and rate-dependent behaviour of a shear-zone soil from a landslide in a gently-inclined mudstone-sandstone sequence in the Sichuan basin, China. Engineering Geology, 237: 1-11.

India Today (2019). Monsoon mayhem: Over 50 killed as 9 states face flood fury, red alert in Kerala. 10 August 2019.

Jamieson, B. and Stethem, C. (2002). Snow avalanche hazards and management in Canada: challenges and progress. Natural Hazards, 26(1): 35-53.

Knap, A.H. and Rusyn, I. (2016). Environmental exposures due to natural disasters. Reviews on environmental health, 31(1): 8992.

Mishra, A.K., and Singh, V.P. (2010). A review of drought concepts. Journal of hydrology, 391(1-2), 202-216.

Mooney, C.C. (2007). Storm world: hurricanes, politics, and the battle over global warming. Houghton Mifflin Harcourt; p. 20.

Newhall, C.G. and Self, S. (1982). The volcanic explosivity index (VEI) an estimate of explosive magnitude for historical volcanism. Journal of Geophysical Research, 87(C2): 1231-1238.

NOAA (2006). What is a Drought? National Oceanic and Atmospheric Administration. August 2006. Retrieved 2007-04-10.

Nwigwe, C. and Emberga, T.T. (2014). An Assessment of causes and effects of flood in Nigeria. Standard Scientific Research and Essays, 2(7): 307-315. 
Ohnaka, M. (2013). The Physics of Rock Failure and Earthquakes. Cambridge University Press. p. 148.

Rothery, D.A. (2010). Volcanoes, Earthquakes and Tsunamis, Teach Yourself.

Schweizer, J., Bruce Jamieson, J. and Schneebeli, M. (2003). Snow avalanche formation. Reviews of Geophysics, 41(4): 10-15.

Sibson, R.H. (1982). Fault Zone Models, Heat Flow, and the Depth Distribution of Earthquakes in the Continental Crust of the United States. Bulletin of the Seismological Society of America, 72 (1):151-163.

Swain, S., Patel, P. and Nandi, S. (2017). Application of SPI, EDI and PNPI using MSWEP precipitation data over Marathwada, India. IEEE International Geoscience and Remote Sensing Symposium (IGARSS). doi:10.1109/ igarss.2017.8128250.

Tate, E. L., and Gustard, A. (2000). Drought definition: a hydrological perspective. In Drought and drought mitigation in Europe. Springer, Dordrecht :23-48.

Tingsanchali, T. (2012). Urban flood disaster management. Procedia engineering, 32: 25-37.

USGS (2004). U.S. Department of the Interior. U.S. Geological Survey, https://pubs.usgs.gov/fs/2004/3072/fs-20043072.html

Varnes, D.J. (1958). Landslide types and processes. Landslides and engineering practice, 24: 20-47.

Vassiliou, M. and Hiroo, K. (1982). The energy release in earthquakes. Bull. Seismol. Soc. Am., 72: 371-387.

Vogt, J.V. and Somma, F. (Eds.; 2013). Drought and drought mitigation in Europe. Springer Science and Business Media. 14.

Wang, Q., Shi, P., Lei, T., Geng, G., Liu, J., Mo, X., Li, X., Zhou, H. and Wu, J. (2015). The alleviating trend of drought in the Huang-Huai-Hai Plain of China based on the daily SPEI. International Journal of Climatology, 35(13): 3760-3769. doi:10.1002/joc.4244.

Wayne, P. (1965). Meteorological Drought. Research paper no.45, U.S. Department of Commerce Weather Bureau, 58.

Young, D.A. (2016). Volcano, Mind over Magma: The Story of Igneous Petrology. Archived from the original on November $12,2015$.

Cite this chapter as: Kamboj, N., Bisht, A., Kamboj, V., Pandey, N. and Bisht, A. (2020). Role of natural disasters in environmental degradation: An overview. In: Environmental Degradation: Causes and Remediation Strategies, Volume 1, Eds. Kumar, V., Singh, J. and Kumar, P., pp. 21-35, https://doi.org/10.26832/aesa-2020-edcrs-02 